\title{
Water, Vapor, and Salt Dynamics in a Hot Repository
}

\author{
Davood Bahrami ${ }^{1}$, George Danko ${ }^{1}$, and John Walton ${ }^{2}$ \\ ${ }^{1}$ Department of Mining Engineering, University of Nevada, Reno, 1664 N. Virginia St., Reno, \\ NV, 89557 \\ ${ }^{2}$ Department of Civil Engineering, University of Texas at El Paso, 500 W. University, El Paso, \\ TX, 79968
}

\begin{abstract}
The purpose of this paper is to report the results of a new model study examining the high temperature nuclear waste disposal concept at Yucca Mountain using MULTIFLUX, an integrated indrift- and mountain-scale thermal-hydrologic model. The results show that a large amount of vapor flow into the drift is expected during the period of above-boiling temperatures. This phenomenon makes the emplacement drift a water/moisture attractor during the above-boiling temperature operation.

The evaporation of the percolation water into the drift gives rise to salt accumulation in the rock wall, especially in the crown of the drift for about 1500 years in the example. The deposited salts over the drift footprint, almost entirely present in the fractures, may enter the drift either by rock fall or by water drippage. During the high temperature operation mode, the barometric pressure variation creates fluctuating relative humidity in the emplacement drift with a time period of approximately 10 days. Potentially wet and dry conditions and condensation on salt-laden drift wall sections may adversely affect the storage environment. Salt accumulations during the above-boiling temperature operation must be sufficiently addressed to fully understand the waste package environment during the thermal period. Until the questions are resolved, a below-boiling repository design is favored where the Alloy-22 will be less susceptible to localized corrosion.
\end{abstract}

\section{INTRODUCTION}

The goal of the new model study is to examine the high temperature nuclear waste disposal concept at Yucca Mountain (YM). The concept involves complex, nonlinear, coupled, typically multi-physics thermal-hydrologic processes in the emplacement area. ${ }^{1-3}$ Examination of such a complex thermalhydrologic problem requires an integrated, multi-scale solution. Models which include the edge-cooling phenomena must be used, such as multi-scale thermohydrologic models (MSTHM) applied for the baseline design by Buscheck et al. ${ }^{2}$, Danko and Bahrami ${ }^{4,5}$, Manepally and Fedors ${ }^{6}$ and Birkholzer et al. ${ }^{7}$

Buscheck et al. ${ }^{2}$ applied the superposition of four sub-models: (a) a three-dimensional (3-D), smeared-source, mountain-scale heat conduction-only model; (b) a line-averaged, two-dimensional (2-D), drift-scale thermohydrologic model; (c) a smeared-heat-source, one-dimensional, drift-scale heat conduction model; and (d) a drift-scale, discrete-source, 3-D, heat conduction and radiation model, based on effective thermal conductivities. The effect of condensation was simulated separately with another, added model $^{3}$. The effect of ventilation during pre-closure was also simulated separately, using an independent ventilation model ${ }^{8}$, de-coupled from the MSTHM. The effect of rock drying caused by preclosure ventilation was not included in the MSTHM. Re-coupling ventilation to the thermohydrologic model was accomplished by reducing the waste heat load output by the amount of heat removed by the air in the MSTHM. Heat and vapor transport along the drift axis were not modeled. Neither model-element captured the mountain-scale moisture transport, therefore, the superposition model may not be considered accurate for predicting humidity and condensate distributions.

Danko ${ }^{4}$ applied MULTIFLUX in which an integrated drift- and mountain-scale rockmass model was coupled to the in-drift model with air movement, configured as a lumped-parameter Computational Fluid Dynamic (CFD) model. However, the mountain-scale model-element used a preliminary configuration that incorporated only heat conduction. 
A more advanced porous media model-element was used for the rockmass in a subsequent analysis ${ }^{5}$. The current study uses MULTIFLUX with this advanced model configuration. Manepally and Fedors ${ }^{6}$ modeled the multi-scale problem by coupling a 3-D mountain-scale model with the 2D drift-scale model. The mountain-scale domain was modeled by an analytical conduction-only model for heat transfer. The conduction model was based on a line load heat source not taking into account the individual waste package characteristics. The mountain-scale edge cooling effect was estimated based on the ratio of the temperature at any location along the drift to the temperature at the center of the drift where there was no edge cooling assumed. This cooling effect was incorporated into the drift-scale 2-D model as a heat load reduction factor. The model did not overcome the basic weaknesses of Buscheck's solution ${ }^{2}$ regarding humidity and condensate distributions.

Birkholzert et al. ${ }^{7}$ studied the post-closure thermal-hydrologic environment in the drift airspace and in the rockmass with a unified model. The airspace was represented with an equivalent, porous-media model within the TOUGH $2^{9}$ rockmass model. Effective transport properties were calculated from the CFD simulation results of Webb and Itamura ${ }^{10}$. Air and/or superheated steam flows were modeled in the drift airspace, as flows in porous media within TOUGH2, two simplifications that may affect in-drift thermal and humidity conditions.

\section{THEORY}

MULTIFLUX is a fully-coupled, hydrothermal-ventilation model and software code which is used to model the flow of heat, moisture, and air in a subsurface airway within the conceptual, high-level nuclear waste repository proposed to be built at YM. The hydrothermal-ventilation/heat flow model connects the heat and moisture transport in two different domains: (1) the in-rock porous media using NUFT ${ }^{11}$, and (2) the in-drift airway with the heat-generating nuclear waste packages, using a lumped-parameter CFD model.

The rockmass is modeled by the porous media model and software NUFT ${ }^{11}$ in order to identify the representative transport characteristics of the rockmass in the form of linear or non-linear, single-, or multi-variable matrix equations for heat and moisture. The model identification is based on the numerical transport code functionalization (NTCF) technique ${ }^{12}$. In general, the NTCF matrix model is a function of input drift wall temperature, vapor pressure, and model constant matrices which provides an approximate solution for the heat and moisture fluxes across the drift wall. Using the NTCF matrix model allows for fast calculation of drift wall fluxes without the need of running the full NUFT model repeatedly during model iterations with different input drift wall temperature and vapor pressure.

\section{DISCUSSION}

\section{Temporal and spatial model domain}

The conceptual repository arrangement follows the conceptual design ${ }^{2}$ developed by DOE. One emplacement drift at the center location of an emplacement panel is selected for the analysis. The transport of moist air along the length of the drift may give rise to moisture condensation along the relatively cold edge sections.

Temperature and RH variations are analyzed from the beginning of waste emplacement for a 5000year period that includes two distinct thermal cycles: during pre-closure and during post-closure. During pre-closure, the drift is mechanically ventilated with a forced (i.e., powered), constant airflow rate of 15 $\mathrm{m}^{3} / \mathrm{s}$ for 50 years. After pre-closure, the access shafts and connecting tunnels are backfilled and sealed, and the emplacement drifts are exposed only to natural air movement. It is assumed that the emplacement drifts are not backfilled, and that the gradual collapse of the drifts, over time, will not prevent natural air movement around the waste packages.

Post-closure, natural airflow in the drift will develop due to the temperature differences between the waste package surfaces and the drift wall. The large eddies caused by the vertical air movement will effectively establish an axial transport of heat and moisture along the drift by dispersion. Although other 
axial transport mechanisms may also be present during post-closure, such as axial, buoyancy-pressuredriven air infiltration through the mountain ${ }^{5,13}$, these effects are disregarded in the present analysis. Under certain conditions in the emplacement drift, condensation may occur, generating liquid-phase water on the drift rock or waste package surfaces, or in the air. The hydrothermal model configured in the lumpedparameter CFD of MULTIFLUX includes model elements that describe the natural, small-scale air movement and related psychrometric processes in the emplacement drift.

The model domains for the rockmass and in-drift airspace are based on an updated model configuration of the baseline case used in a previous study ${ }^{14}$. The results of the in-drift relative humidity variation as a result of barometric pressure variations are also updated in the present study with a refined model relative to a previous study ${ }^{14}$.

\section{Moisture and salt accumulation distributions}

The vapor inflow into the drift airspace is depicted in Figure 1a. Figure $1 \mathrm{~b}$ shows the water attraction ratio, a non-dimensional ratio between the spatial and temporal vapor flux into the drift and the model input percolation water flux calculated over the springline width, $\mathrm{D}$, of the drift. The $\mathrm{W}$ in the W/D water attraction ratio may be pictured as an imaginary width over which the natural ambient water percolation flux is collected, and transported into the drift by evaporation or seepage. In the domain where W/D $>1$, the drift is effectively a water attractor. This domain approximately coincides with the spatial and temporal domain where the temperature is above-boiling.

It must be recognized that part of the increased vapor inflow to the drift during the first few hundred years comes from the evaporation of initial pore water. The seven-fold water attraction ratio, W/D, over $70 \%$ of the drift length at year 75 indicates the combination of rock dehydration and an increased capillary flow towards the drift.

Using the matrix and fracture porosity and water saturation values applied in the model, the total, initial water content in the maximum dryout zone above the drift crown is about $0.5 \mathrm{~m}^{3}$ over each $1 \mathrm{~m}^{2}$ of the horizontal footprint in the hot drift section. This amount is equivalent of 45 years of recharge from initial percolation flux, and represents an insignificant portion (approx. $2 \%$ ) of the evaporated water, that is higher than the percolation inflow, over 2000 years.
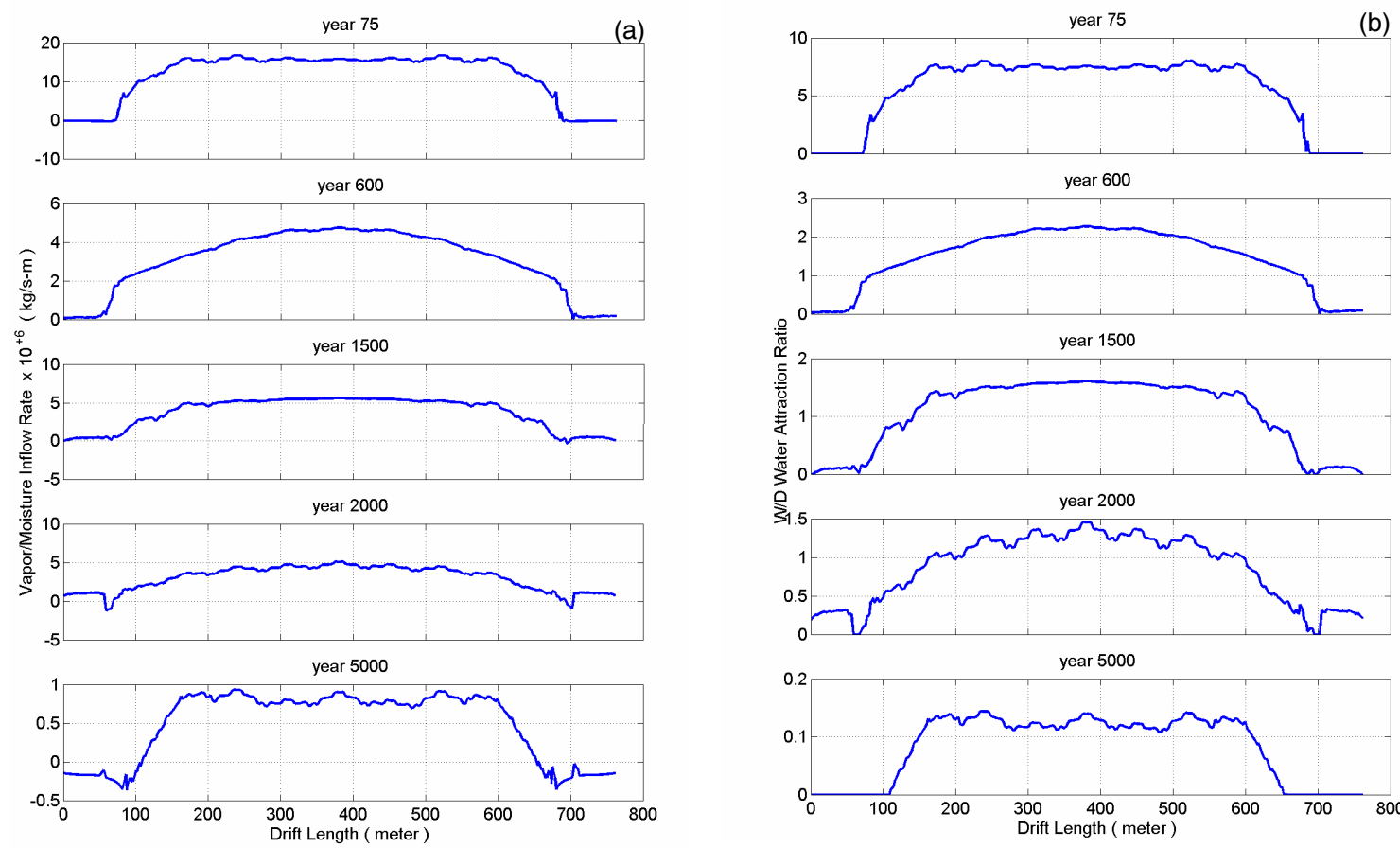

(b)

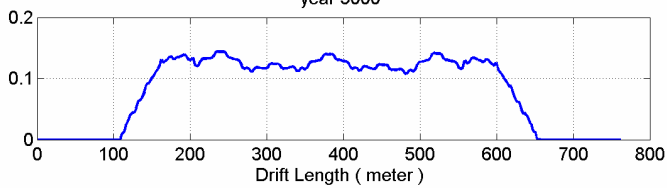

Figure 1. Drift moisture inflow (a) and water attraction ratio distributions (b) along the drift length at selected post-closure time periods. 


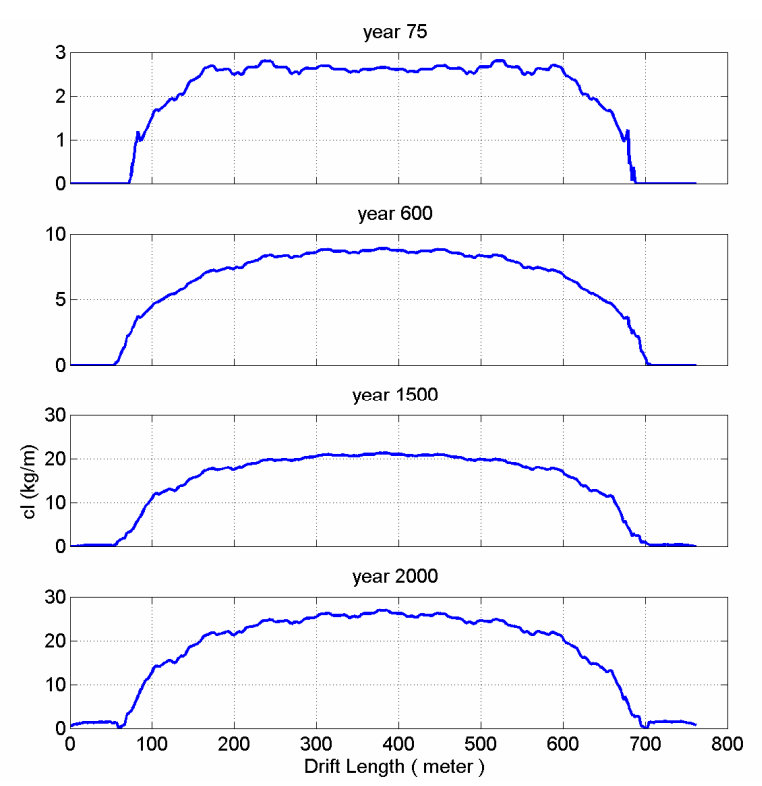

Figure 2. Salt accumulation in the rock above the drift footprint.

The immediate consequence of evaporation from the drift wall into the air space is that dissolved ions from the source water will precipitate and accumulate as solids in the rock pores and fractures. Figure 2 is an upper estimate of chloride ion $\left(\mathrm{Cl}^{-}\right)$accumulation, associated with evaporation of water over the drift width, D, as a function of the drift length at selected postclosure time periods. The chloride accumulation at this point is a hypothesis based on the assumption that the concentration of chloride in pore water is $117 \mathrm{mg} / \mathrm{L}$ at $\mathrm{YM}^{15}$, and that the total amount of chloride is deposited in the rock wall during complete evaporation. The numerical model results are used only within the boundaries of total evaporation with no percolating liquid water leaving a control volume of the rockmass.

Examination of the water and flow directions in the rockmass reinforces the dissolved ion accumulation hypothesis with the new model results. Figure 3 shows water and vapor flow patterns from the NUFT model-element in the fractured and porous rockmass surrounding the emplacement drift in its middle section at three different time instants. Until year 1500, at which time the drift is significantly below-boiling, all percolating water disappears and turns into vapor form. Evidence of total evaporation of percolation water is seen in Figures $3 \mathrm{a}$ and $3 \mathrm{~b}$. The liquid water flow above the drift width dead-ends in the rockmass, and becomes a vapor source, as shown in the diverging vapor flow fields in Figures $3 \mathrm{~d}$, $3 \mathrm{e}$ and $3 \mathrm{f}$. A minute diversion of the percolation water flow at the drift crown is seen at year 2000 in Figure 3c, indicating the onset of potential solute discharge and the effect of drift shadow. Vapor flow is still active all around the perimeter including the drift crown and the floor, as depicted in Figure $3 \mathrm{f}$, showing that accumulation and discharge may coexist for some time.

Salt accumulation likely continues to 2000 years at which time the onset of water flow and horizontal diversion begins to appear, seen in Figure 3c. Nearly all of the accumulated vapor inflow originates from the evaporation of percolating water as opposed to the evaporation of the initial pore water in the rock. Salts deposited by the evaporation of the percolating water are likely to be deposited in or near fractures or other high permeability areas within the dryout zone between the drift wall and the maximum extent of the boiling front. 

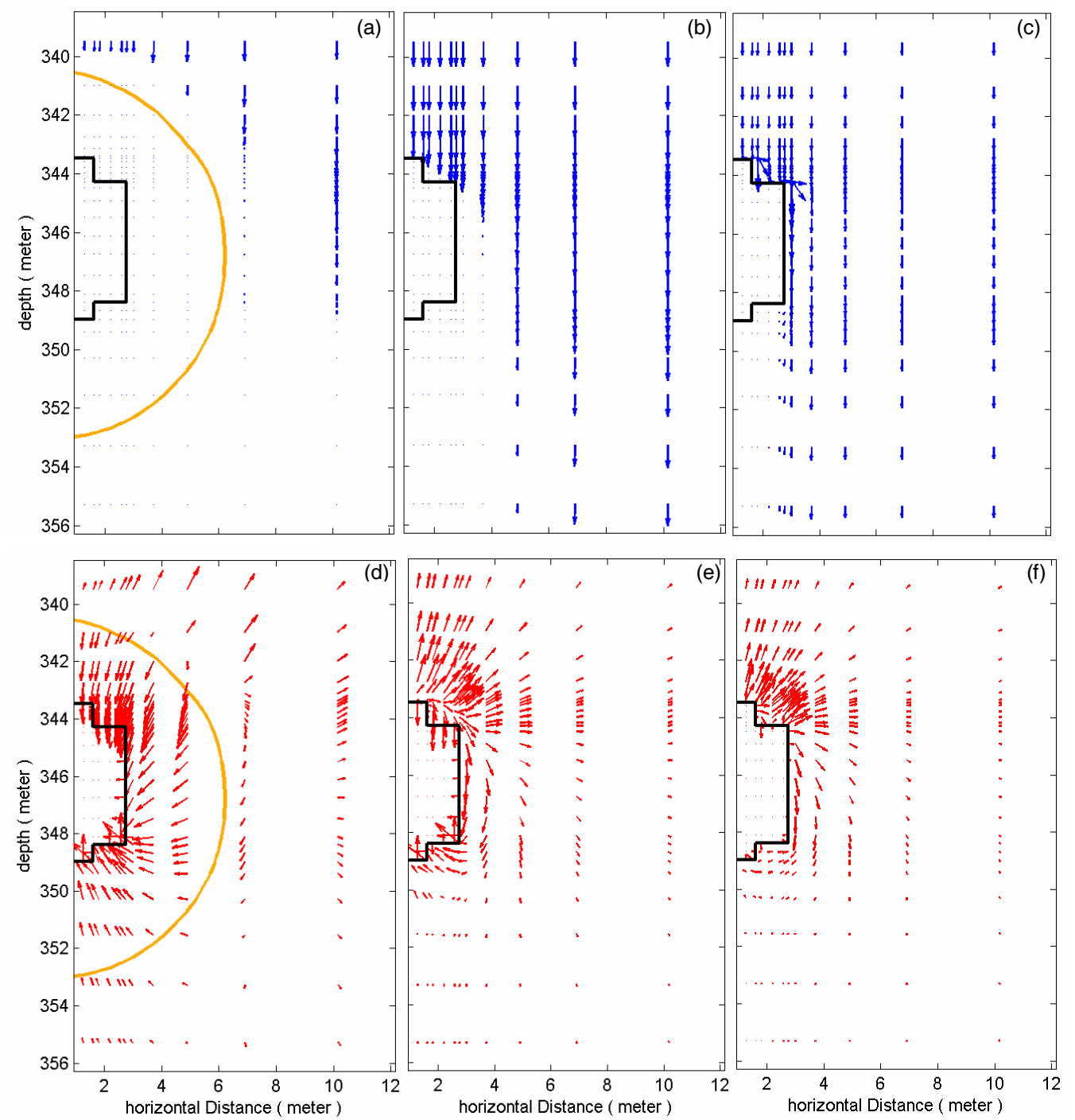

Figure 3. Water velocity in the rock mass surrounding the emplacement drift in liquid phase (upper row, a, b, c) and gas phase (lower row, d, e, f) at year 600 (a, d); year 1500 (b, e); year 2000 (c, f); solid line indicates $96{ }^{\circ} \mathrm{C}$ contour, the boiling temperature at YM.

The liquid flow velocity vectors above the drift are essentially vertical until $~ 2,000$ years, at which time lateral diversion of water around the drifts has begun to occur. The vertical velocity vectors indicate that mobile salts deposited at early time periods at distance above the drift will be transported toward the drift roof as the dryout zone rewets. Interestingly, the three dimensional modeling predicts no liquid flow at the rock/drift interface for a time period exceeding 1500 years in the hot drift section. A critical time period is seen between years 1500 and 2000, when the drift wall is already at below-boiling temperature. This is the time period when dripping of concentrated salt solutions onto the waste package may occur as a result of episodic water flow into the drift, a transient phenomena that has been studied by others ${ }^{16}$.

The predicted salt accumulation is determined from the accumulated vapor inflow for the thermal period during which no horizontal water flow diversion is present. Salts precipitated from substantially immobile water located in the rock matrix may be largely inaccessible, however, this fraction represents only a very small portion (a few \%) of the total salts. Future numerical simulation will be required to assess the location of the salt deposits relative to the drift wall and the dynamics of salts deposition in the drift wall. 


\section{Effect of barometric pressure variation}

The effect of static barometric pressure alteration for 5000 years was studied in a previous work ${ }^{14}$ using a small, embedded rockmass NUFT model. The embedded, 2-D model described vertical and horizontal heat and moisture flows in the vertical plane normal to the drift centerline in the rockmass around a 1-m-long drift section in the hottest, central section of the drift. The barometric pressure within the drift was assumed to follow the fluctuations measured daily for barometric pressure at several observation points at and around Yucca Mountain. Based on measurement results, a simplified, equivalent, square-wave pressure variation with approximately 10 day time period was established using statistical evaluation, described in previous work ${ }^{14}$ in more detail.

The amplitude and the frequency of the square wave were respectively those of the RMS (root-meansquare) and of the dominant frequency from Fourier analysis of the measured barometric pressure variation. The square-wave barometric pressure variation with 200 full periods was then applied as a boundary condition to the simplified NUFT rockmass model to study the effect upon the drift wall heat and moisture/vapor fluxes. The results showed that either a positive or negative change in the barometric pressure significantly changed the heat and moisture fluxes during the time period with above-boiling temperatures. The MULTIFLUX iterations were slow with the high barometric pressure half-waves (during which time the moisture/vapor flow direction would change from into-the-drift to into-the-rock), therefore, only half of the pressure variation was used in the simulation by chopping-off the high cycle part and replacing it with the average barometric pressure value. The ratio between the moisture/vapor fluxes for the lowest and the average barometric pressure values was determined for MULTIFLUX model processing. Detailed description of the model set up and solution is given in a previous study ${ }^{14}$. This study has been repeated with the same pressure input data, but with a refined model configuration in MULTIFLUX.

Figure 4 shows at selected post-closure time divisions the new results for the high and the low barometric pressure cycles in terms of axial distribution of drift wall condensation rate and $\mathrm{RH}$ obtained from the MULTIFLUX simulation. The shaded area represents the variation between upper and lower bounds due to the variation in barometric pressure. The cycles of relative humidity are of potential importance in corrosion of the waste containers or other barriers.

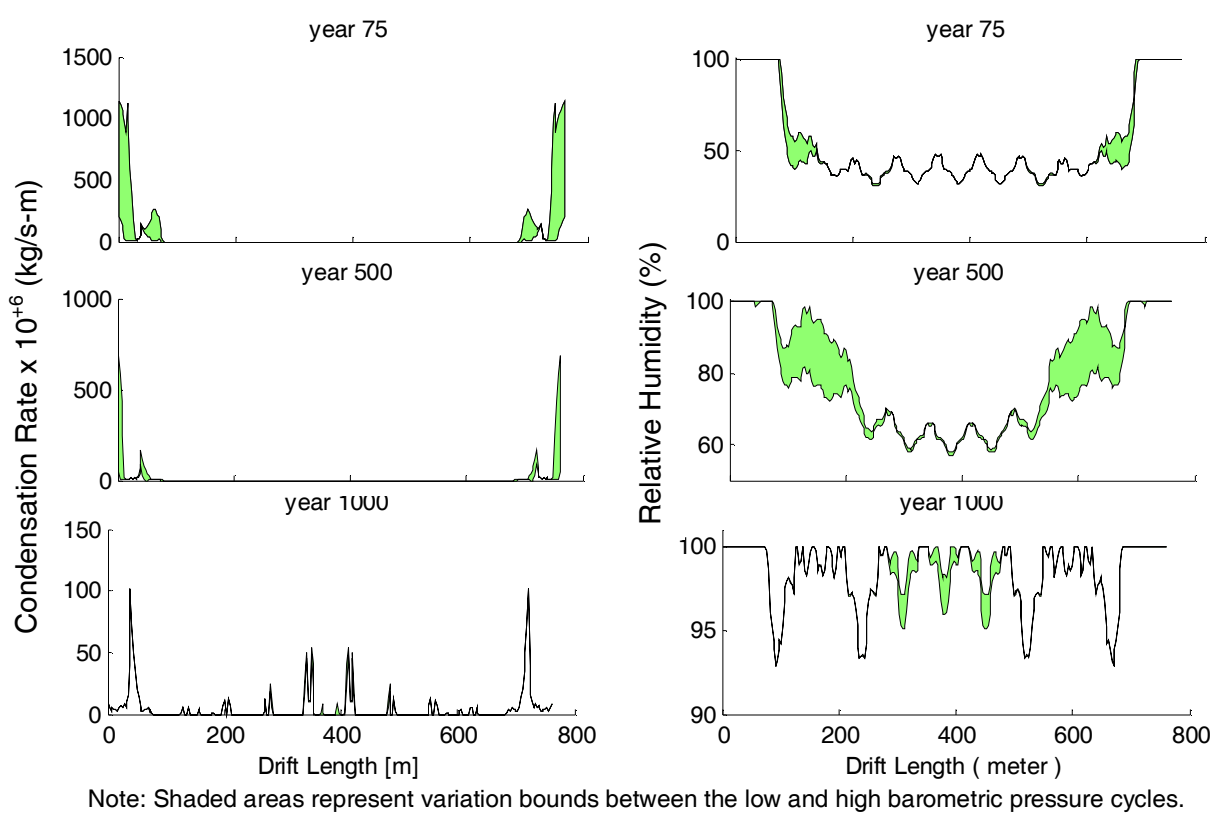

Figure 4. Upper and lower condensation and relative humidity bounds on the drift surface based on periodic pressure variations between the high and the low pressure values. Condensation rate and relative humidity will swing between the upper and lower bounds with approximately a 10-day cycle time period. 


\section{CONCLUDING REMARKS}

Numerical simulation with a coupled in-rock and in-drift model in MULTIFLUX predicts temperature, humidity, as well as heat and moisture flows. Three dimensional simulation results clearly illustrate the dominant influence of longitudinal transport of vapor along the drifts on the water balance. Longitudinal transport of vapor along the drifts in response to the gradient in absolute humidity changes the flow system in and around the emplacement drifts. Especially important is the central portion of the drifts where vapor flow is predicted into the drifts during the thermal period, as opposed to away from the drift from previous models that assume a closed hydrothermal system.. The net evaporation with resultant dead end flow paths for liquid water is anticipated to deposit salts at the evaporation locations. Most of this evaporation comes from percolating water rather than water initially in the rock matrix, meaning the deposited salts are potentially mobile during rewetting. The location and amounts of deposited salts relative to the drift wall is a subject of ongoing work; the results shown in the paper are partial accumulations deposited by total evaporation of dead-end flow, in the dryout zone above the crown of the drift.

The enhanced role of longitudinal water vapor transport in the drifts is also related to the dynamics of the system. Historically, analysts have tended to view the time variance of evaporation, condensation, and relative humidity in the engineered barrier system as a nearly static, slowly evolving, stationary state system. Three-dimensional modeling with consideration of barometric pressure variation and changes in thermal differences between waste packages suggests that a more dynamic system will exist in an above boiling repository. Relative humidity, evaporation, and condensation are anticipated to vary along the drifts as a function of changes in barometric pressure. The drift wall may vary between dry and wet periodically during the time period when at least part of the emplacement drift is at above boiling temperature. Corrosion tests obtained from static environments may be inadequate to confidently predict corrosion behavior in dynamic, cyclical environments.

Given the complexity and dynamic nature of the engineered barrier system in an above boiling repository and the paucity of experimental data and modeling analysis under these conditions, perhaps a below-boiling-temperature solution is preferable. A below boiling repository will greatly reduce the amounts of moisture evaporation and redistribution in the mountain, as illustrated by the characteristics of the results with sharp changes with respect to temperature decrease.. The location and time evolution of

the salt deposits and cyclic behavior of the system are important subjects for further research for both the above- and the below-boiling-temperature design options.

\section{ACKNOWLEDGMENTS}

The work was supported by the Nye County Nuclear Waste Repository Project Office.

\section{REFERENCES}

1. DOE (U.S. Department of Energy)., “Thermal Loading Study for FY 1996.” B00000000-017175705-00044 REV 01. Las Vegas, Nevada: CRWMS M\&O. ACC: MOL.19961217.0121 (1996).

2. DOE (U.S. Department of Energy). "Multiscale Thermohydrologic Model". Prepared by Bechtel SAIC Company, LLC. ANL-EBS-MD-000049 REV 01. Yucca Mountain Project. Las Vegas, Nevada (2004).

3. Bechtel SAIC Company, "In-drift natural convection and condensation." Yucca Mountain Project Report, MDL-EBS-MD-000001 REV 00, Bechtel SAIC Company, Las Vegas, NV (2004).

4. G. Danko, "Coupled Hydrothermal-Ventilation Studies for Yucca Mountain." Annual Report for Period April 2002 through March 2003. Pahrump, Nevada: Nye County Department of Natural Resources. WRPO-2003-5 (2003).

5. G. Danko, and D. Bahrami, "Coupled, Multi-Scale Thermohydrologic-Ventilation Modeling with MULTIFLUX” 2004 SME Annual Meeting, February 23-25, Denver, CO (2004). 
6. C. Manepally, and R. Fedors, "Edge-Cooling Effect on the Potential Thermohydrologic Conditions at Yucca Mountain." Proceedings, 10th Int. High-Level Radioactive Waste Management Conference, pp. 286-292 (2003).

7. J.T. Birkholzer, S.W. Webb, N. Halecky, P.F. Peterson, and G.S. Bodvarsson, "Evaluating the Moisture Conditions in the Fractured Rock at Yucca Mountain: The Impact of Natural Convection Processes in Heated Emplacement Drifts.” LBNL-59334, Berkeley, CA, Lawrence Berkeley National Laboratory (2005).

8. DOE (U.S. Department of Energy). "Ventilation Model." Prepared by Bechtel SAIC Company, LLC. ANL-EBS-MD-000030 REV 01D draft. Yucca Mountain Project. Las Vegas, Nevada (2002).

9. K. Pruess, C. Oldenburg, and G. Moridis, "TOUGH2 User's Guide, Version 2.0.” Report LBNL43134, Lawrence Berkeley National Laboratory, Earth Sciences Division, Berkeley, California (1999).

10. S. W. Webb, and M. T. Itamura, "Calculation of Post-Closure Natural Convection Heat and Mass Transfer in Yucca Mountain Drifts." Proceedings of ASME, Heat Transfer/Fluid Engineering, July 11-15, Charlotte, NC (2004).

11. NUFT. "Flow and Transport Code Version 3.0s." Software Configuration Management, Yucca Mountain Project - STN: 10088-3.0S-00. Prepared by Lawrence Livermore National Laboratory (2000).

12. G. Danko, "Functional or Operator Representation of Numerical Heat and Mass Transport Models." Journal of Heat Transfer, February 2006, Vol. 128, 162-175 (2006).

13. G. Danko, and D. Bahrami, "Heat and Moisture Flow Simulation with MULTIFLUX", Proceedings of HT-FED04 - ASME Heat Transfer/ Fluids Engineering Summer Conference, Charlotte, NC (2004).

14. G. Danko, and D. Bahrami, "Coupled Hydrothermal-Ventilation Studies for Yucca Mountain." Annual Report for April 2004-March 2005. NWRPO-2005-02, prepared for Nye County Department of Natural Resources and Federal Facilities, Pahrump, NV (2005).

15. Yucca Mountain Project Technical Database [TDR-NBS-MD-000001, 2000].

16. J. Birkholzer, "Penetration of liquid fingers into superheated fractured rock" Water Resources Research, Vol 39, No 4, 1102, (2003). 